\title{
An uncommon entity of primary ovarian fibroid: a case report
}

\author{
Ramesh Bettaiah $^{1}$, Shraddha Neminath Kurkuri ${ }^{1 *}$, Vanishree B. R. $^{2}$, Chaithra T. M. ${ }^{1}$
}

\author{
${ }^{1}$ Department of Gynaecological Endoscopy \& Infertility, Dr Ramesh Hospital, Bangalore, Karnataka, India \\ ${ }^{2}$ Department of Pathology, Dr Ramesh Hospital, Bangalore, Karnataka, India
}

Received: 21 January 2016

Revised: 28 January 2016

Accepted: 17 February 2016

\section{*Correspondence:}

Dr. Shraddha Neminath Kurkuri,

E-mail: snk3061988@gmail.com

Copyright: ( ) the author(s), publisher and licensee Medip Academy. This is an open-access article distributed under the terms of the Creative Commons Attribution Non-Commercial License, which permits unrestricted non-commercial use, distribution, and reproduction in any medium, provided the original work is properly cited.

\begin{abstract}
Ovarian fibroid is a rare solid benign tumor that accounts for 0.5 to $1 \%$ of all benign ovarian tumors and approximately 70 cases have been reported in literature till date. Most of these tumors are unilateral, small in size and generally occur in premenopausal women. It is usually diagnosed incidentally during pelvic examination or pathological examination after surgery. The origin of ovarian fibroid is still unresolved. We here in present a case of 31-year-old woman with primary infertility diagnosed to have right primary ovarian fibroid with an endometriotic cyst in the same ovary presenting with pain abdomen. She underwent laparoscopic tumor resection with cystectomy. Ovarian fibroid was confirmed by immunohistochemical study. Despite its rarity, ovarian fibroid should be considered in the differential diagnosis of ovarian spindle cell tumors. This is a rare case of primary ovarian fibroid with review of literature, especially highlighting the need for conservative ovary-preserving surgery in reproductive age group women.
\end{abstract}

Keywords: Ovarian fibroid, Ovary, Histopathology, Immunohistochemistry, Conservative surgery

\section{INTRODUCTION}

Ovarian fibroids (ovarian leiomyomas), either primary or parasitic in origin, account for about $0.5 \%$ to $1 \%$ of all benign ovarian tumors. ${ }^{1}$ In literature, reported cases are between 17 and 79 years of age. ${ }^{2,3}$ Due to their rarity, about 70 cases of primary ovarian fibroids have been reported worldwide. ${ }^{1}$ The majority of these tumors are discovered incidentally, with about $80 \%$ of the cases occurring in premenopausal women. ${ }^{4}$ Patients are usually asymptomatic, and the tumor is most commonly diagnosed unintentionally by histological examination and confirmed by immunohistochemical analysis. ${ }^{5}$ Most of these tumors are unilateral, measure only few millimeters in diameter. They probably arise from smooth muscle cells in the ovarian hilar blood vessels but other possible origins include cells in the ovarian ligament, smooth muscle cells or multipotential cells in the ovarian stroma, undifferentiated germ cells, or cortical smooth muscle metaplasia. ${ }^{6-8} \mathrm{We}$ here in describe a case of 31 years old lady with right ovarian fibroid with endometriotic cyst in the same ovary, which was managed conservatively by laparoscopic tumor resection and endometriotic cystectomy. We have also reviewed the existing available literature on this rare tumor.

\section{CASE REPORT}

A 31 years old lady with primary infertility (married for 8 years) presented with history of right lower abdominal pain on and off since 1 month to our hospital. She had a normal menstrual pattern. On examination, a mobile, non-tender mass separate from the uterus was felt in the right fornix. On transvaginal ultrasound, right adnexal solid mass which was well circumscribed with homogeneously isoechoic pattern and with no pathological blood flow pattern in Doppler was identified (Figure 1). Pre-operatively, our provisional diagnosis was of subserosal or broad ligament fibroid. She was operated for both infertility and abdominal pain. On laparoscopy, a solid, irregular in shape, firm mass, with well-defined 
margins and smooth surface arising from right ovary measuring about $6 \times 4 \mathrm{~cm}$ was visualized, distinctly separate from the uterus with no adhesions or infiltration to the surrounding structures (Figure 2). There was also a small endometriotic cyst measuring about $1 \times 1.5 \mathrm{~cm}$ in the same ovary, just adjacent to the mass (Figure 3). We proceeded with laparoscopic resection of right ovarian mass in the endobag keeping in mind the solid lesions of ovary including malignancy thereby preventing spillage of malignant cells and also endometriotic cystectomy (Figure $4-6$ ). Both specimens were sent for pathological examination (Figure 7). On cut section, the ovarian mass showed (solid in consistency) greyish-white whorled areas (Figure 8). Microscopically, it showed a normal ovarian tissue with smooth muscle cells separated by connective tissues and no significant mitosis, pleomorphism or necrosis was noted (Figure 9). The tumor cells were diffusely and strongly positive for desmin confirming the diagnosis of ovarian leiomyoma (Figure 10). The lumen of the endometriotic cyst was covered with cuboidal epithelial cells without signs of atypia, surrounded by endometrial-type stroma. There were hemosiderin laden macrophages and extravasated red blood cells in the vicinity of the cyst (Figure 11).

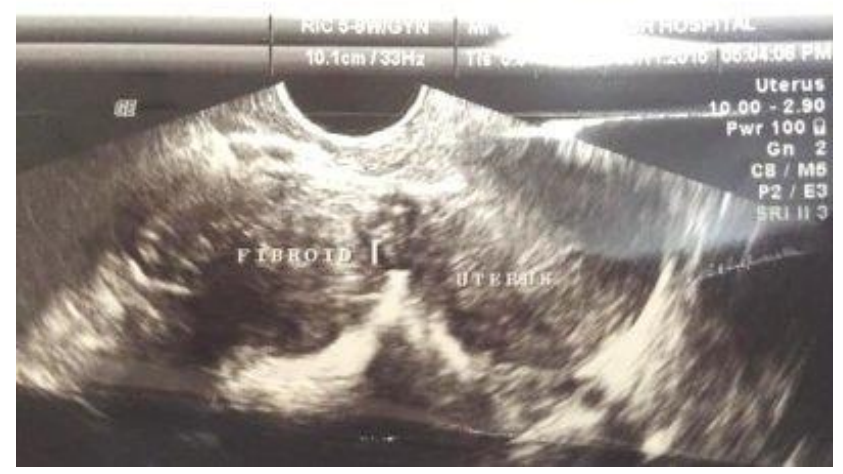

Figure 1: Transvaginal ultrasound image showing the right adnexal mass (ovarian fibroid) adjacent to the uterus.

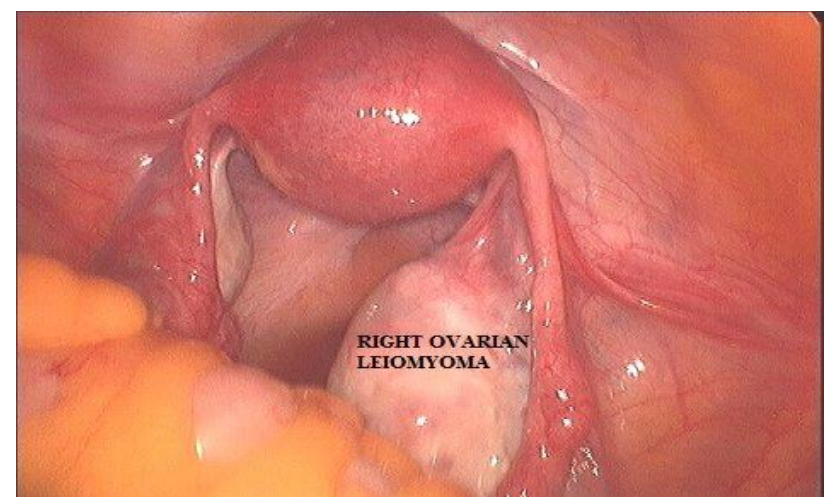

Figure 2: Laparoscopic view of right ovarian fibroid seen separately from the uterus along with right ovarian endometriotic cyst.

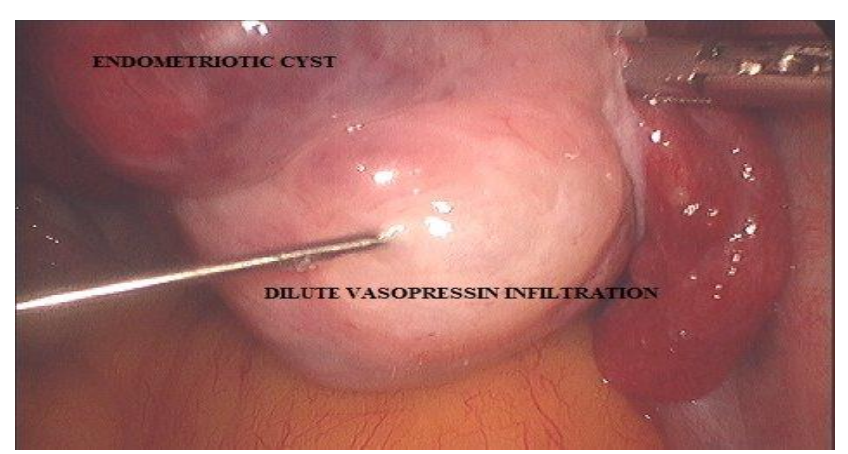

Figure 3: Infiltration of dilute vasopressin between the tumour and the overlying ovarian tissue.

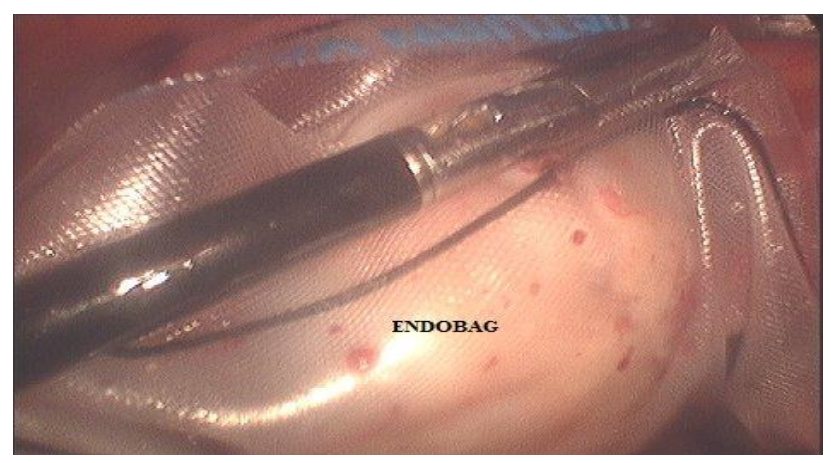

Figure 4: Introduction of the whole ovary into the endobag before resection.

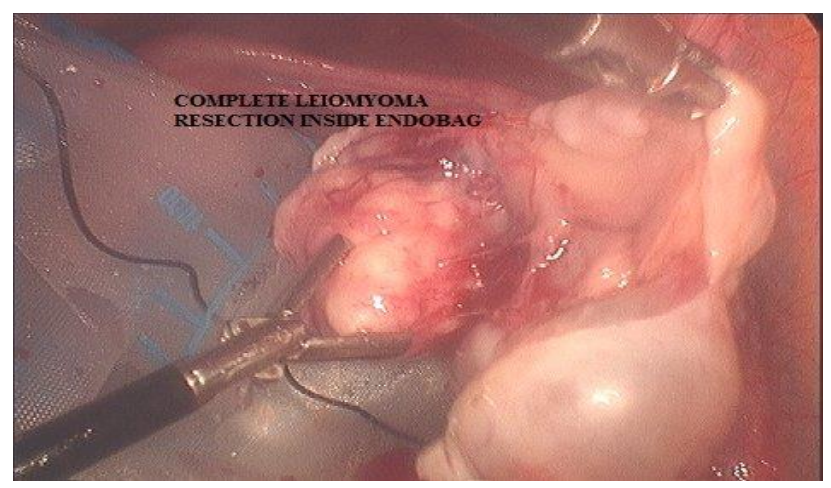

Figure 5: Resection of the tumour completely inside the endobag.

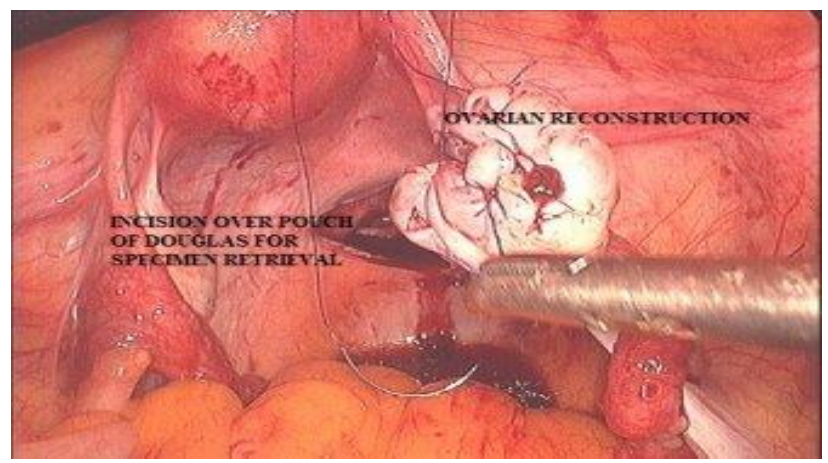

Figure 6: Reconstruction of the right ovary after tumour resection and cystectomy. 


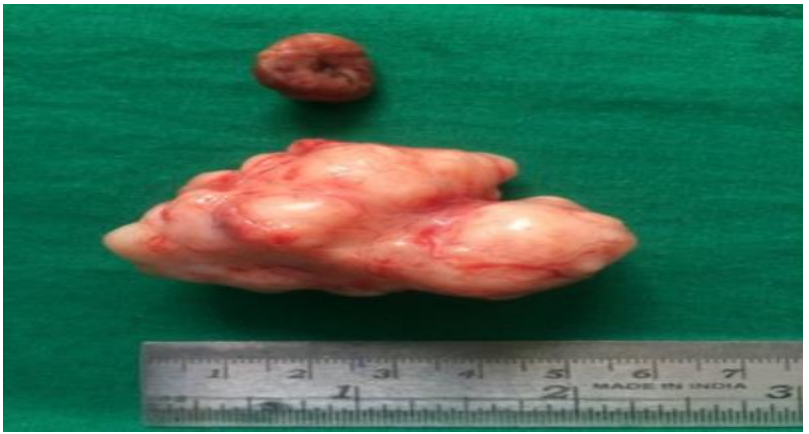

Figure 7: Gross appearance of ovarian fibroid ( 6 x 4 $\mathrm{cm})$ and endometriotic cyst $(1.5 \times 1 \mathrm{~cm})$.

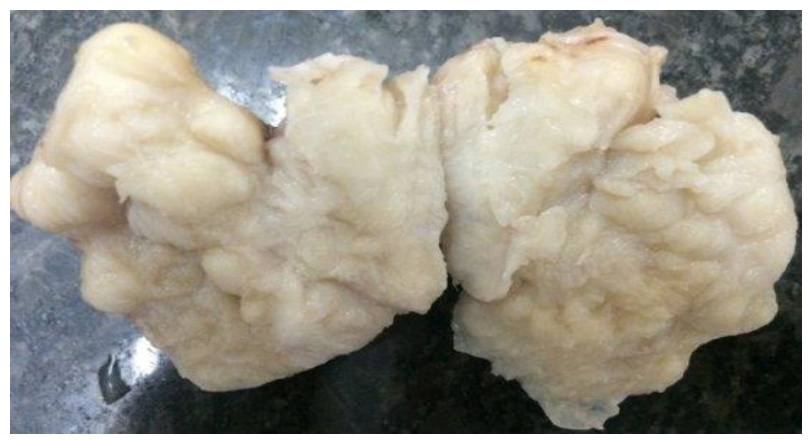

Figure 8: Cut section of ovarian fibroid showing greyish-white whorled areas.

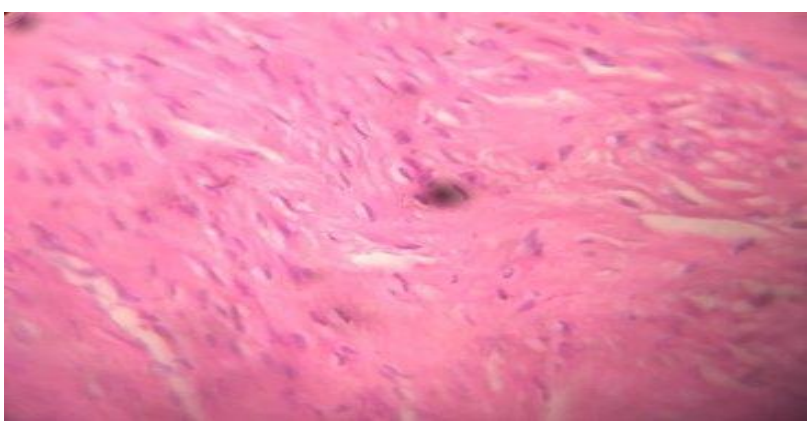

Figure 9: Microscopic view of ovarian fibroid showing smooth muscle cells separated by connective tissues $(45 x)$.

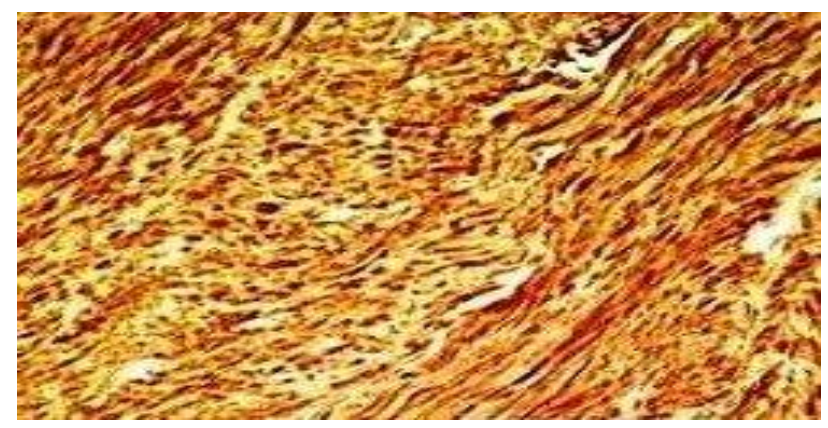

Figure 10: Tumour cells showing diffuse strong positivity for desmin (Immunohistochemical analysis $-100 x)$.

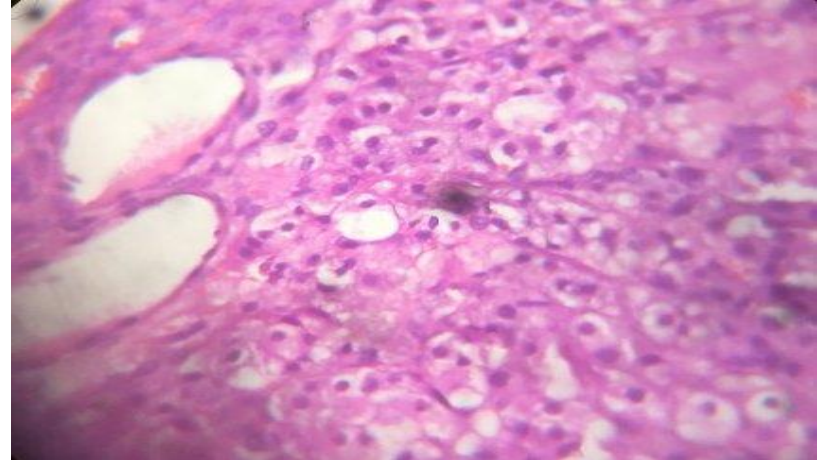

Figure 11: Microscopic view of endometriotic cyst $(45 x)$.

\section{DISCUSSION}

A primary fibroid of the ovary is a very rare case and approximately 70 cases are reported in the literature since Sangalli first described this tumor in 1862. Even though the cases have reported that primary ovary fibroid occurred in postmenopausal women, most primary ovarian fibroids were reported in premenopausal women. ${ }^{9}$ However, postmenopausal patients represent approximately $16 \%$ of cases. ${ }^{10}$ All relevant articles on ovarian fibroid were taken from Medline and Cochrane database for review.

The size of primary ovarian fibroid is usually $<3 \mathrm{~cm}$, the size of the tumor is relatively large in our case [9]. They may also reach big size up to $11 \mathrm{~kg}$. Most of these tumors are unilateral. Interestingly, most of the bilateral cases are diagnosed in young patients. The oldest age reported in a bilateral case is 35 years. $^{11,12}$

Ovarian fibroids are mainly asymptomatic and are discovered accidentally during pelvic examination or imaging or operation for uterine fibroid or other pathologies. ${ }^{13}$ A rare presentation was reported by Kurai et al., who reported fibroid of the ovary presenting with Meigs syndrome, which disappeared after removal of the ovary. ${ }^{3}$ Other rare presentations have included acute abdominal pain mimicking appendicitis, lower abdominal mass, ascites with hydrothorax, ascites with polymyositis, ascites with elevated CA125 or even hydronephrosis as a consequence of its huge size. ${ }^{12,14-18}$ Ovarian fibroid often may be misdiagnosed preoperatively as pedunculated uterine myoma, ovarian fibroma or even ovarian endometrioma. The presence of normal ovarian tissue beside the tumor confirms the ovarian origin of the tumor and excludes tumors of other origins, such as leiomyoma of broad ligament or a subserous leiomyoma that grew large and lost its attachments to the uterus (wandering leiomyoma). ${ }^{10,19}$

Because of the rarity of the condition, primary ovarian fibroids are not diagnosed initially by ultrasonography or radiography. Ultrasound has been well documented as the best diagnostic modalities for pelvic organ masses, but in 
ovarian fibroids, it is difficult to distinguish ovarian fibroids from other ovarian tumors. Even on CT of abdomen and pelvis, it is difficult to distinguish ovarian fibroids from other ovarian masses, and sometimes, the ovarian mass is reported as a malignancy. ${ }^{20}$

The histogenesis of ovarian fibroid is not well known. Some theories hypothesize that the tumor may originate from hilar blood vessels, smooth muscle metaplasia of ovarian stroma, or smooth muscle-like theca externa cells. ${ }^{13}$ Its association with uterine fibroid may suggest that they share the same mechanisms of development. This theory is explained by the rapid growth of such tumors during pregnancy and their positivity for estrogen and/or progesterone receptors. ${ }^{13}$ Ovarian fibroid are concomitantly seen with uterine fibroid $(78 \%)$, that suggest an identical hormonal stimulation., ${ }^{21}$ The literature has reported that many patients with ovarian fibroids are nulligravida. This also suggests that oestrogen may play a role in the development of ovarian fibroids. ${ }^{2}$ Tomas et al. have suggested that ovarian fibroid could arise from smooth muscle metaplasia of endometriotic stroma, or it could be derived from myofibroblasts that originate from metaplastic ovarian stromal cells present in the rim of the endometriotic cyst especially if the tumor was associated with endometriosis or endometriotic cysts. ${ }^{12}$

Apart from fibroid there are other ovarian tumors that show a spindle cell microscopic appearance. Fibroma is the most common ovarian spindle cell neoplasm, but other neoplasms of the sex cord-stromal group may contain spindle cells and the differential diagnoses may include thecoma, granulosa cell tumor, Sertoli-Leydig cell tumor, sclerosing stromal tumor, and signet-ring stromal tumor. ${ }^{22}$ To confirm the diagnosis and rule out other causes the immunohistochemical staining with desmin, inhibin, and $\alpha$-smooth muscle actin ( $\alpha$-SMA) or histochemical staining with Masson's trichrome should be done. The leiomyoma cells will stain with Masson's trichrome, desmin $\alpha$-SMA and h-caldesmon. ${ }^{23}$

Sometimes it may be difficult to differentiate between ovarian fibroid and ovarian fibroma, but Lerwill et al concluded in their study that smooth muscle tumors show diffuse desmin reaction while fibromatous tumors show either negativity or focal positivity with desmin. ${ }^{13}$ Also, smooth muscle actin is often positive in fibromatous tumors, so it is not useful to differentiate between the two tumors. ${ }^{13}$ Malignant potential is suspected if the tumor is huge, despite its benign microscopic picture. ${ }^{24}$ Cellular thecoma could be also considered in differential diagnosis but they express $\alpha$-inhibin and calretinin and do not express smooth muscle actin. ${ }^{12,25}$

A similar case of ovarian adenomyoma associated with endometriotic cyst was described by McDougal and Roth. ${ }^{26}$ An adenomyoma presenting outside the uterus is an extremely rare entity. Adenomyoma is a circumscribed tumor like mass consisting of endometroid glands, stroma, and smooth muscle tissue. ${ }^{26,27}$ In our case after taking multiple sections of the specimen, it showed no any additional stromal or glandular element in tumor and diagnosis of adenomyoma was excluded. Fukunaga showed that smooth muscle metaplasia in ovarian endometriosis is not a rare event and that its frequency was about $18 \% .^{28}$

Ovarian fibroid must be also differentiated from leiomyosarcoma but due to its rarity these tumors histological features of malignancy have not been well defined. Pathologists have traditionally used criteria that stress on the mitotic count, but it is evident that some other criteria, such as cytological atypia and tumor necrosis must be used when considering the possibility of malignancy in a smooth muscle tumor Spindle cell carcinoma, and metastatic gastrointestinal stromal tumors also should be excluded in case of large tumors. ${ }^{10,12,29,30}$ Lerwill et al., described smooth muscle tumors of ovary exhibiting the same varied histological spectrum as their uterine counterparts. However, unlike the case with uterine fibroids, the histological features of malignancy for ovarian smooth muscle tumors have not been well defined. ${ }^{24,29}$

A common surgical approach to ovarian fibroids in middle-aged to elderly patients is hysterectomy in conjunction with bilateral salpingo-oophorectomy. Most of the patients undergo salpingo-oophorectomy or oophorectomy with or without hysterectomy despite the young age of affliction, and only minor of patients are submitted to an ovary-preserving surgery. Wei et al. reported a case in which pedunculated unilateral ovarian fibroid and in which ovarian preservation was possible. ${ }^{5}$ In our case also, we performed laparoscopic resection of the tumor only (ovary-preserving surgery) thus preserving fertility. Patient is doing well, abdominal pain has subsided now.

All cases of ovarian fibroids demonstrate an excellent prognosis without recurrence despite the active mitosis observed in the tumor. ${ }^{31}$ Therefore we all should make a best possible effort to perform less invasive surgery, particularly in young women, to preserve fertility. ${ }^{32}$ Indeed, it has been suggested that endoscopy be the approach of choice because of its acknowledged advantages, including minimal trauma, superb visualization, low incidence of complications, reduced chances of adhesion formation, rapid recovery \& cosmetic effect.

\section{CONCLUSIONS}

Thyroid storm is an acute, life-threatening, hyper metabolic state in individuals with thyrotoxicosis. Diagnosis is primarily clinical, and no specific laboratory tests are available. Several factors may precipitate the progression of thyrotoxicosis to thyroid storm. Because thyroid storm is almost invariably fatal if left untreated, rapid diagnosis and aggressive treatment is fundamental 
in limiting the maternal, fetal and neonatal morbidity and mortality associated with this condition.

Funding: No funding sources

Conflict of interest: None declared

Ethical approval: Not required

\section{REFERENCES}

1. Van Esch EM, van Wijngaarden SE, Schaafsma HE, Smeets MJ, Rhemrev JP. The diagnostic and therapeutic approach of a primary bilateral leiomyoma of the ovaries: a case report and a literature review. Arch Gynecol Obstet. 2011;283:1369-71.

2. Lim SC, Jeon HJ. Bilateral primary ovarian leiomyoma in a young woman: case report and literature review. Gynecol Oncol. 2004;95(3):733-5.

3. Kurai M, Shiozawa T, Noguchi H, Konishi I. Leiomyoma of the ovary presenting with Meigs' syndrome.J Obstet Gynaecol Res. 2005;31:257-62.

4. Blue NR, Felix JC, Jaque J. Primary ovarian leiomyoma in a premenarchal adolescent: first reported case. J Pediatr Adolesc Gynecol. J Pediatr Adolesc Gynecol. 2014;27(4):e87-8.

5. Wei C, Lilic N, Shorter N, Garrow E. Primary ovarian leiomyoma: a rare cause of ovarian tumor in adolescence. J Pediatr Adolesc Gynecol. 2008;21(1):33-6.

6. Emovon EU, Cahill DJ, Joels LA, Stegmann MH. Bilateral primary ovarian leiomyoma: a rare cause of ovarian tumour in a young woman. J Obstet Gynaecol. 1999;19:676.

7. Kim JC, Nam SL, Suh KS. Leiomyoma of the ovary mimicking mucinous cystadenoma. Clin Imaging. 2000;24:34-7.

8. Doss BJ, Wanek SM, Jacques SM, Qureshi F, Ramirez NC, Lawrence WD. Ovarian smooth muscle metaplasia: an uncommon and possibly underrecognized entity. Int $\mathbf{J}$ Gynecol Pathol. 1999; 18:58-62.

9. Güney M, Ozsoy M, Oral B, Mungan T, Kapucuoglu $\mathrm{N}$. Unilateral primary ovarian leiomyoma in adolescent: a case report. Arch Gynecol Obstet. 2007;275(6):507-10.

10. Ramalakshmi Pullela VB, Das S, Chunduru B, Dua S. A case of ovarian leiomyoma with cystic degeneration. Indian J Pathol Microbiol. 2009;52:592-4.

11. Khaffaf N, Khaffaf H, Wuketich S. Giant ovarian leiomyoma as a rare cause of acute abdomen and hydronephrosis. Obstet Gynecol. 1996;87:872-3.

12. Tomas D, Lenicek T, Tuckar N, Puljiz Z, Ledinsky M, Kruslin B. Primary ovarian leiomyoma associated with endometriotic cyst presenting with symptoms of acute appendicitis: A case report. Diagn Pathol. 2009;4:25.

13. Lerwill MF, Sung R, Oliva E, Prat J, Young RH. Smooth muscle tumors of the ovary: A clinicopathologic study of 54 cases emphasizing prognostic criteria, histologic variants, and differential diagnosis. Am J Surg Pathol. 2004;28:1436-51.

14. Mathew M, Krolikowski A, Al-Haddabi I, Nirmala V. Primary ovarian leiomyoma. Saudi Medical Journal. 2005;26(2):306-7.

15. Nicoll JJ, Cox PJ. Leiomyoma of the ovary with ascites and hydrothorax. American Journal of Obstetrics and Gynecology. 1989;161(1):177-8.

16. van Winter JT, Stanhope CR. Giant ovarian leiomyoma associated with ascites and polymyositis. Obstetrics and Gynecology. 1992;80(3):560-3.

17. Erdemoglu E, Kamaci M, Bayram I, Güler A. Primary giant leiomyoma of the ovary-case report," European Journal of Gynaecological Oncology. 2006;27(6):634-5.

18. Khaffaf N, Khaffaf, and S. Wuketich, "Giant ovarian leiomyoma as a rare cause of acute abdomen and hydronephrosis. Obstetrics and Gynecology. 1996;87(5):872-3.

19. Tsalacopoulos G, Tiltman AJ. Leiomyoma of the ovary: A report of 3 cases. S Afr Med J. 1991;11:574-6.

20. Paladini D, Testa A, Van Holsbeke C, Mancari R, Timmerman D, Valentin L. Imaging in gynecological disease: clinical and ultrasound characteristics in fi broma and fi brothecoma of the ovary. Ultrasound Obstet Gynecol. 2009;34:188-95.

21. Usta U, Karadag N, TÜrkmen E, Haltas H. Primary leiomyoma of the ovary. Balkan Med J. 2006;23:3942.

22. McCluggage WG. Immunohistochemical markers as a diagnostic aid in ovarian pathology. Diagnostic Histopathology. 2008;14(8):335-51.

23. Al-Shaikh AF, Darwish A, Nagaraj V, Alsada A. A rare combination of ovarian and uterine leiomyomas with goblet cell carcinoid of the appendix. Case Rep Surg. 2015:467243.

24. Murakami M, Uehara H, Nishimura M, Iwasa T, Ikawa H. A huge ovarian smooth muscle tumor: A case report. J Med Invest. 2010;57:158-62.

25. Ozcimen EE, Oktem M, Zeyneloglu HB, Ozdemir $\mathrm{BH}$, Kuscu E. Primary leiomyoma of the ovary in a young woman: Literature review and report of a case. Eur J Gynaecol Oncol. 2006;27:310-2.

26. McDougal RA, Roth LM: Ovarian adenomyoma associated with an endometriotic cyst. South J Med. 1986;79:640-2.

27. Mandal S, Mahajan D, Khurana N. Ovarian adenomyoma mimicking an ovarian malignancy: a case report with literature review. Int J Surg Pathol. 2009; 17:38-40.

28. Fukunaga M. Smooth muscle metaplasia in ovarian endometriosis. Histopathology. 2000;36:348-52.

29. Lerwill MF, Sung R, Oliva E, Prat J. Smooth muscle tumors of the ovary: a clinicopathologic study of 54 cases emphasizing prognostic criteria, histologic variants, and differential diagnosis. The American Journal of Surgical Pathology. 2004;28(11):1436-51. 
30. Costa MJ, Morris R, DeRose PB, Cohen C. Histologic and immunohistochemical evidence for considering ovarian myxoma as a variant of the thecoma-fibroma group of ovarian stromal tumors. Arch Pathol Lab Med. 1993;117:802-8.

31. Bucella D, Limbosch JF, Buxant F, Simon P, Fayt I, Anaf $\mathrm{V}$, et al. Recurrence of mitotically active cellular fibroma of the ovary. Obstet Gynecol Int. 2009;2009:803062.

32. Son CE, Choi JS, Lee JH, Jeon SW, Hong JH, Bae JW. Laparoscopic surgical management and clinical characteristics of ovarian fibromas. JSLS. 2011;15:16-20.

Cite this article as: Bettaiah R, Kurkuri SN, Vanishree BR, Chaithra TM. An uncommon entity of primary ovarian fibroid: a case report. Int J Reprod Contracept Obstet Gynecol 2016;5:927-32. 